Vol. 11 (1): 97-102 (2021)

\title{
A RETROSPECTIVE STUDY (2017-2019) ON THE SEROPREVALENCE OF BRUCELLOSIS IN LOCAL AND IMPORTED CATTLE IN DIFFERENT ALGERIAN REGIONS
}

\author{
Khaled Ouared $^{1 *}$ \\ ${ }^{1 *}$ Institute of Veterinary Sciences University Ibn-Khaldoun of Tiaret, Algeria; \\ "Corresponding Author Khaled Ouared, e-mail: e-mail: kouaredvet14@gmail.com;
}

Received November 2020; Accepted December 2020; Published January 2021;

DOI: $\underline{\text { https://doi.org/10.31407/ijees11.113 }}$

\begin{abstract}
Bovine brucellosis recognized by the OIE as a major endemic zoonoses, caused by the bacterium Brucella abortus. The aim of this study was to determine the seroprevalence to Brucella abortus in local and imported cattle breeds Algeria between 2017 to 2019.During the three years a total of 63284 local and 63180 imported cattle in different Algerian regions were sampled. The samples were analyzed using serological tests (RBPT and ELISA) of the local cattle sera analysed, 447 (Prevalence 1.89\%),321(prevalence 11.13\%) and $213(1.51 \%$ ) were found to be positive by RBPT and ELISA, respectively. Of the imported cattle sera analysed screened were a cas RBPT positive. The study reports the first evidence of bovine brucellosis over a vast geographical area of western Algeria Between (20172019) and therefore, an indication of a real animal and humans health problem. This warrants the need of integrated intervention to New strategies to fight this disease.
\end{abstract}

Keywords: bovine; brucellosis; seroprevalence; potential risk factors; Algeria. 